\title{
A single parameter representation of hygroscopic growth and cloud condensation nucleus activity - Part 2: Including solubility
}

\author{
M. D. Petters and S. M. Kreidenweis \\ Department of Atmospheric Science, Colorado State University, CO, USA \\ Received: 12 February 2008 - Published in Atmos. Chem. Phys. Discuss.: 25 March 2008 \\ Revised: 27 August 2008 - Accepted: 27 August 2008 - Published: 29 October 2008
}

\begin{abstract}
The ability of a particle to serve as a cloud condensation nucleus in the atmosphere is determined by its size, hygroscopicity and its solubility in water. Usually size and hygroscopicity alone are sufficient to predict $\mathrm{CCN}$ activity. Single parameter representations for hygroscopicity have been shown to successfully model complex, multicomponent particles types. Under the assumption of either complete solubility, or complete insolubility of a component, it is not necessary to explicitly include that component's solubility into the single parameter framework. This is not the case if sparingly soluble materials are present. In this work we explicitly account for solubility by modifying the single parameter equations. We demonstrate that sensitivity to the actual value of solubility emerges only in the regime of $2 \times 10^{-1}-5 \times 10^{-4}$, where the solubility values are expressed as volume of solute per unit volume of water present in a saturated solution. Compounds that do not fall inside this sparingly soluble envelope can be adequately modeled assuming they are either infinitely soluble in water or completely insoluble.
\end{abstract}

\section{Introduction}

The supersaturation required to activate a particle into a cloud droplet depends on the particle size and on its constituent hygroscopicities, and solubilities. Classical Köhler theory provides the relationship between critical supersaturation and dry diameter for particles composed of a single, hygroscopic compound that is fully dissolved at the wet critical diameter, i.e. the diameter where the particle activates.

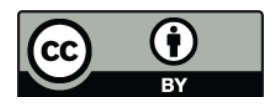

Correspondence to: M. D. Petters (petters@atmos.colostate.edu)
It was recognized early on, however, that particles do not consist of single components but are mixtures of a variety of compounds, some of which may be effectively water insoluble. To treat these cases, extensions of Köhler theory were proposed that decomposed the particle into an insoluble core immersed in an aqueous-ionic solution. As a result, $\mathrm{CCN}$ activity has often been associated with the water soluble fraction, and, erroneously, with the solubility of the particle. It was not until fairly recently that Köhler equations considering multiple components, each having limited solubility, have been proposed (Laaksonen et al., 1998; Shulman et al., 1996). Accounting for limited solubility has enabled successful prediction of the unusual CCN activities of sparingly soluble compounds (Bilde and Svenningsson, 2004; Hori et al., 2003; Broekhuizen et al., 2004; Henning et al., 2005).

Recently Petters and Kreidenweis (2007), hereafter, PK07, suggested that a single hygroscopicity parameter can effectively model the CCN activity of atmospheric particles, including those containing insoluble components. Other, essentially equivalent, expressions have been suggested in the literature (e.g., Rissler et al., 2006) and a review about the origin of single parameter expressions is given in PK07. The PK07 framework is built on the premise that (1) water soluble components are fully dissolved at dilutions relevant to $\mathrm{CCN}$ activation, and (2) some sparingly soluble components behave as completely insoluble over the full range of relevant dilutions, and do not contribute to water uptake. Hence no explicit treatment of solubility is necessary. Under these conditions it is the aerosol hygroscopicity, i.e. the amount of water per unit volume of dissolved solute, that determines the subsaturated water content and the relationship between particle dry diameter and critical supersaturation. Because the equations in PK07 do not include solubility,

Published by Copernicus Publications on behalf of the European Geosciences Union. 
solubility-controlled CCN activation phenomena cannot be modelled. Here we build on PK07 by explicitly including solubility into their framework, using the formulations presented by Raymond and Pandis (2003) and Bilde and Svenningsson (2004). Our equations are valid for the entire range of hygroscopicities and solubilities. We include an algorithm that can be used to efficiently calculate the relationship between critical supersaturation and dry diameter for an arbitrary number of components of specified mass or volume fraction, and selected dry particle size. Finally, we identify a narrow range of solubilities that delineates an effectively insoluble regime from an effectively soluble regime.

\section{Generalized $\kappa$-Köhler equations}

The saturation ratio, $S$, over an aqueous solution droplet can be calculated from

$S=a_{w} \exp \left(\frac{4 \sigma_{s / a} M_{w}}{R T \rho_{w} D}\right)$

where $a_{w}$ is the activity of water in solution, $\rho_{w}$ is the density of water, $M_{w}$ is the molecular weight of water, $\sigma_{s / a}$ is the surface tension of the solution/air interface, $R$ is the universal gas constant, $T$ is temperature, and $D$ is the diameter of the droplet. PK07 proposed a hygroscopicity parameter $\kappa$ that is defined through its effect on the water activity of the solution:

$\frac{1}{a_{w}}=1+\kappa \frac{V_{s}}{V_{w}}$,

where $V_{s}$ is the volume of the dry particulate matter (both soluble and insoluble) and $V_{w}$ is the volume of the water. For a multicomponent system with multiple solutes and water at equilibrium, for which the Zdanovskii, Stokes, and Robinson (ZSR) assumption applies, the total volume of the water is the sum of the water contents due to the individual components, i.e. $V_{w}=\sum V_{w i}$, and the individual $V_{w i}$ are obtained for $a_{w i}=a_{w}$. Applying the ZSR assumption and rearranging Eq. (2) for $V_{w}$ gives:

$V_{w}=\frac{a_{w}}{1-a_{w}} \sum_{i} \kappa_{i} V_{s i}$

The total volume of the system (water + solute) is

$V_{T}=\sum_{i} V_{s i}+\sum_{i} V_{w i}=V_{s}+V_{w}$

where $V_{s}=\sum V_{s i}$. In Eq. (2) water uptake is assumed to be continuous over the full range $0<a_{w}<1$. Not all substances, however, are infinitely soluble in water and a stable solution is formed only for water contents, and thus water activities, larger than the solubility limit. Here we introduce the dissolved volume fraction of the solute $x_{i}$, defined analogously to Eq. (3) in Raymond and Pandis (2003). For complete dissolution, $x_{i}$ is equal to unity. When $x_{i}$ is less than unity

$x_{i}=C_{i} V_{w} / V_{s i}$, where $C_{i}$ is the solubility of the solute in water, expressed here as volume of compound per unit volume of water. Effects of dissolution kinetics (Asa-Awuku and Nenes, 2007; Kelly et al., 2007) and curvature enhanced solubility (Padro and Nenes, 2007) are not considered by this expression. Rewriting Eq. (3) gives

$$
\begin{aligned}
& V_{w}=\frac{a_{w}}{1-a_{w}} \sum_{i} \kappa_{i} V_{s i} H\left(x_{i}\right) \\
& H\left(x_{i}\right)=\left\{\begin{array}{ll}
x_{i} & x_{i}<1 \\
1 & x_{i} \geq 1
\end{array} .\right.
\end{aligned}
$$

Defining the individual (dry) component volume fractions as $\varepsilon_{i}=V_{s i} / V_{s}$ and recognizing that $V_{w}=V_{T}-V_{s}$, Eq. (3) becomes

$$
\begin{aligned}
& V_{T}-V_{s}=\frac{a_{w}}{1-a_{w}} V_{s} \sum_{i} \varepsilon_{i} \kappa_{i} H\left(x_{i}\right) . \\
& x_{i}=C_{i} V_{w} /\left(V_{s} \varepsilon_{i}\right)
\end{aligned}
$$

If we further assume that the volume change of mixing is zero, $V_{w} / V_{s}=g^{3}-1$, where $g$ is the diameter growth factor $\left(g=D / D_{d}\right), D_{d}$ is the dry diameter, and $x_{i}$ can be alternatively expressed as .

$x_{i}=\left(g^{3}-1\right) C_{i} / \varepsilon_{i}$.

The volumes can be converted to their volume equivalent diameters, $D_{d}^{3}=6 V_{s} / \pi$ and $D^{3}=6 V_{T} / \pi$, respectively. Solving Eq. (6) for $a_{w}$ and combining the result with Eq. (1) yields the generalized $\kappa$-Köhler equation:

$S(D)=\frac{D^{3}-D_{d}^{3}}{D^{3}-D_{d}^{3}(1-\kappa)} \exp \left(\frac{A}{D}\right)$,

where $A=8.69251 \times 10^{-6} \sigma_{s / a} / T$ is a constant that is evaluated at $\sigma_{s / a}=0.072 \mathrm{~J} \mathrm{~m}^{-2}$ and $T=298.15 \mathrm{~K}$ (PK07) and we use these assumed values throughout this manuscript. The overall value for $\kappa$ is given by the following mixing rule:

$$
\begin{aligned}
& \kappa=\sum_{i} \varepsilon_{i} \kappa_{i} H\left(x_{i}\right) \\
& x_{i}=\left(g^{3}-1\right) C_{i} / \varepsilon_{i} \\
& H\left(x_{i}\right)=\left\{\begin{array}{cc}
x_{i} & x_{i}<1 \\
1 & x_{i} \geq 1
\end{array} .\right.
\end{aligned}
$$

Note that Eq. (9) is identical to Eq. (6) in PK07 and that for infinitely soluble substances Eq. (10) reduces to Eq. (7) in PK07. Equations (9) and (10) apply over the entire range of relative humidity, solution hygroscopicity, and solubility. They can be used to predict deliquescence relative humidity and particle water content in the subsaturated $(S<1)$ regime, as well as to predict the conditions for cloud droplet activation. The critical supersaturation $\left(s_{c}\right.$, where $s_{c}=S_{c}-1$ and is usually expressed as a percentage) for a selected dry diameter of a particle having hygroscopicity $\kappa$ is computed from the maximum of the generalized $\kappa$-Köhler curve (Eq. 9). An algorithm for numerically calculating the maximum of Eq. (9) is given in Appendix A. 
Table 1. Physical and chemical properties of compounds used for calculation throughout this manuscript.

\begin{tabular}{llllll}
\hline Compound & $\begin{array}{l}\text { Density } \\
\left(\mathrm{kg} \mathrm{m}^{-3}\right)\end{array}$ & $\begin{array}{l}\text { Molecular weight } \\
\left(\mathrm{g} \mathrm{mol}^{-1}\right)\end{array}$ & $\begin{array}{l}\text { Solubility } \\
\left(\mathrm{g} \mathrm{kg}^{-1}\right)\end{array}$ & $\begin{array}{l}\text { Solubility }(C) \\
\left(\mathrm{m}^{3} \mathrm{~m}^{-3}\right)\end{array}$ & $\begin{array}{l}\text { Hygroscopicity } \\
(\kappa)\end{array}$ \\
\hline Sodium chloride & 2160 & 58.44 & 360 & $1.6 \times 10^{-1 \mathrm{c}}$ & $1.28^{\mathrm{a}}$ \\
Succinic acid & 1560 & 118.09 & 88 & $5.6 \times 10^{-2 \mathrm{~b}}$ & $0.23^{\mathrm{a}}$ \\
Calcium carbonate & 2609 & 100.09 & 0.006 & $2.3 \times 10^{-6 \mathrm{c}}$ & $0.97^{\mathrm{c}}$ \\
\hline
\end{tabular}

a Petters and Kreidenweis (2007)

$\mathrm{b}$ Bilde and Svenningsson (2004)

c Sullivan R. C., Moore M., Petters, M. D., Kreidenweis S. M., Roberts G. C., and Prather, K. A.: Calcium mineral dust particles as CCN 1. Importance of chemical mixing state, J. Phys. Chem.-A, submitted, 2008.

\section{Discussion and conclusions}

We now show that Eqs. (9) and (10) reproduce previously reported complex Köhler curves due to the presence of sparingly soluble components (Shulman et al., 1996; Bilde and Svenningsson, 2004; Hori et al., 2003) and also reproduce the off-kappa-isoline behavior that is observed when plotting critical supersaturation versus dry diameter for sparingly soluble compounds (Hori et al., 2003; Kreidenweis et al., 2006). To demonstrate these effects we use calcium carbonate, succinic acid, and sodium chloride as illustrative compounds. Their physical and chemical properties, including hygroscopicity and solubility are summarized in Table 1. We use these as examples for an effectively insoluble compound $\left(C<5 \times 10^{-4}\right)$, a sparingly soluble compound $\left(5 \times 10^{-4}<C<2 \times 10^{-1}\right)$, and a moderately soluble compound $\left(C>2 \times 10^{-1}\right)$, respectively. Example Köhler curves for pure succinic acid and succinic acid mixed with sodium chloride are presented in Fig. 1. With no solubility limits imposed, i.e. $C=\infty$, the equations predict continuous water uptake over the entire range of $0<\mathrm{RH}<s_{c}$. For moderately soluble species, $C>2 \times 10^{-1}$ as is the case for most inorganic salts, no water uptake is observed until the deliquescence relative humidity (DRH) is reached. The DRH depends on the solubility, the water activity/hygroscopicty of the saturated solution, and the dry particle diameter and, for moderately soluble compounds, is below $95 \% \mathrm{RH}$. DRH is expected to increase with decreasing solubility, decreasing hygroscopicity, and decreasing particle size, leading to cases where deliquescence only occurs under supersaturated conditions. Since deliquescence must occur prior to growth, cloud droplet activation can be controlled by solubility (e.g. single component example presented by the solid line, $C=0.056$, in Fig. 1). Multicomponent systems exhibit even more complex behavior. For the illustrative binary solution, composed of succinic acid and sodium chloride with sodium chloride volume fractions $\varepsilon=0.2,0.5$, and $2 \%$ (dashed lines in Fig. 1), the more soluble compound (sodium chloride) deliquesces at $\mathrm{RH}=75 \%$ (not shown). Some succinic acid can also dissolve when water is present. The dissolved

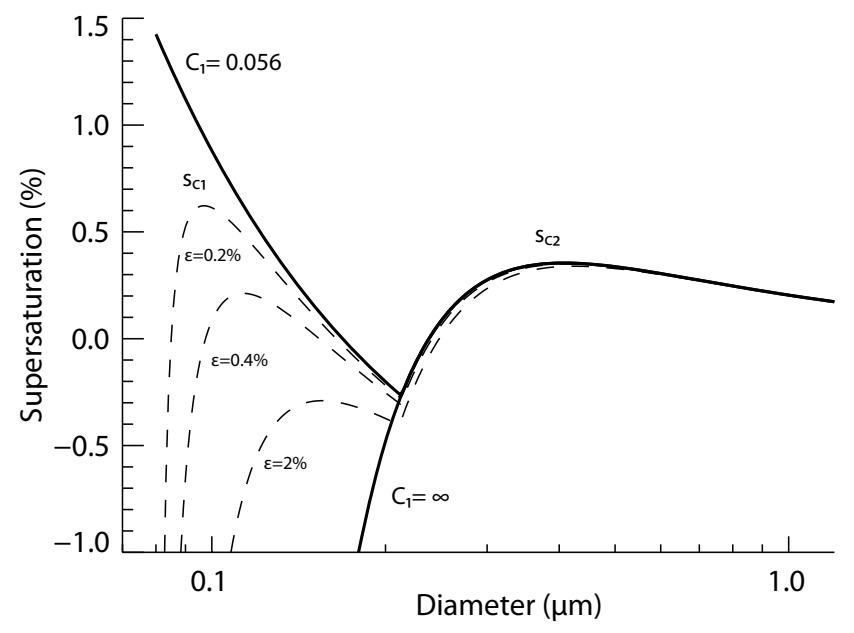

Fig. 1. Example Köhler curves calculated from Eqs. (9) and (10) for pure succinic acid (solid lines, compound 1) and binary solutions of succinic acid and $0.2,0.4$, and $2 \%$ of sodium chloride by volume (dashed lines). The chosen example is similar to Fig. 1b in Bilde and Svennigsson (2004). Physical and chemical properties of sodium chloride assumed in the calculations are summarized in Table 1.

fraction corresponds to that required to form a saturated solution of succinic acid in the available water, assuming applicability of the ZSR approximation. The binary curves exhibit two maxima, denoted $s_{c 1}$ and $s_{c 2}$, separated by a minimum that corresponds to the wet diameter where the succinic acid is fully dissolved. The larger maximum supersaturation $\left(s_{c 1}\right.$ or $s_{c 2}$ ) is expected to control cloud droplet activation (Bilde and Svenningsson, 2004). Figure 1 also raises an important point about the particle diameter at activation, generally referred to as the critical diameter. The critical diameter is not observable in typical CCN instruments and thus must be inferred from theory. Figure 1 shows that the critical diameter, and therefore the water content at activation, is not uniquely determined by the relationship between critical supersaturation and dry diameter. Thus methods that use $\mathrm{CCN}$ data to infer solution molality from these data may be in error. 


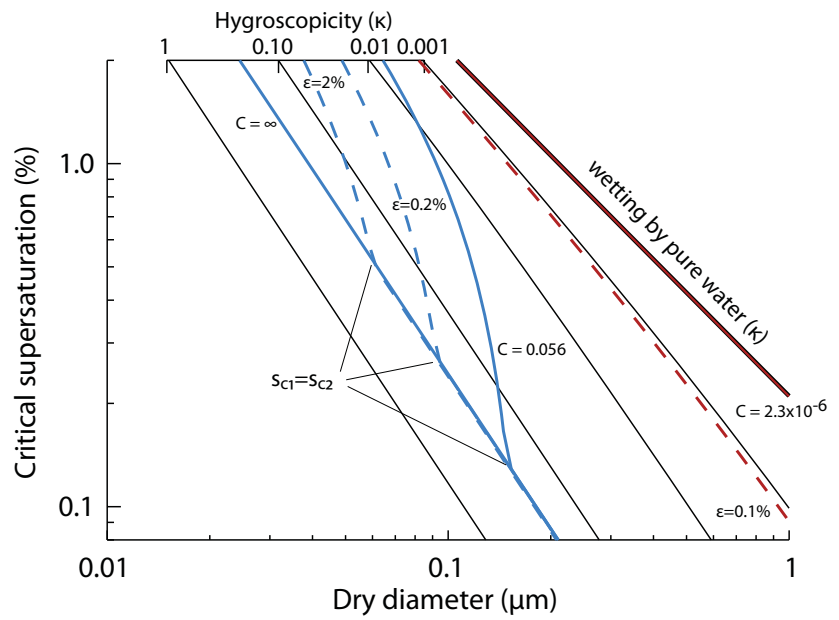

Fig. 2. Predicted CCN activity for single- and two-component mixtures. Blue: assumed hygroscopicity and solubility of dominant component, succinic acid having $\kappa=0.23$ and $C=0.056$. Solid line: pure component; activation proceeds based on the deliquescence $\mathrm{RH}$, which is determined by the water activity of the saturated solution. Dashed lines: addition of $0.2 \%$ and $2 \%$ by volume of sodium chloride. Red: hygroscopicity and solubility of calcium carbonate, $\kappa=0.97$ and $C=2.3 \times 10^{-6}$. Solid line: pure component. Dashed line: addition of $0.1 \%$ by volume of sodium chloride.

Figure 2 shows isolines of $\kappa$ in critical supersaturation $\left(s_{c}\right)$ - dry diameter $\left(D_{\text {dry }}\right)$ space for infinitely-soluble particles (black) and sparingly-soluble succinic acid particles (blue) and effectively insoluble calcium carbonate particles (red). PK07 showed that the CCN activities of pure and complex particle types follow, to a good approximation, lines of constant $\kappa$. For certain solubilities and mixtures, off-isoline behavior is observed, leading to a higher sensitivity of critical supersaturation to dry particle diameter (blue curves). For a single sparingly-soluble compound (blue-solid line) this steep-slope behavior indicates dry diameters where $s_{c 1}>s_{c 2}$. For particles with $D_{d}>\sim 120 \mathrm{~nm}, s_{c 1}<s_{c 2}$ and CCN activity is controlled by the assumed hygroscopicity of succinic acid $(\kappa=0.23)$. Addition of a moderately soluble and hygroscopic compound such as sodium chloride leads to a shift of the steep-sloped region to smaller diameters since the equilibrium water uptake of the infinitely soluble compound leads to partial dissolution of the sparingly-soluble compound. The point where $s_{c 1}=s_{c 2}$ is also reached at smaller dry diameters. Experimentally, the off-isoline behavior has been shown for succinic and adipic acid (Bilde and Svenningsson, 2004; Hori et al., 2003) and perhaps some secondary organic aerosols (Kreidenweis et al., 2006; VanReken et al., 2005) and a humic-like aerosol sample (Ziese et al., 2008). However, to date no observations unequivocally suggest that this behavior is important in atmospheric aerosols. Finally, for very small solubilities, no steep slopes are observed, even in mixtures (red lines). The particles behave as if they were

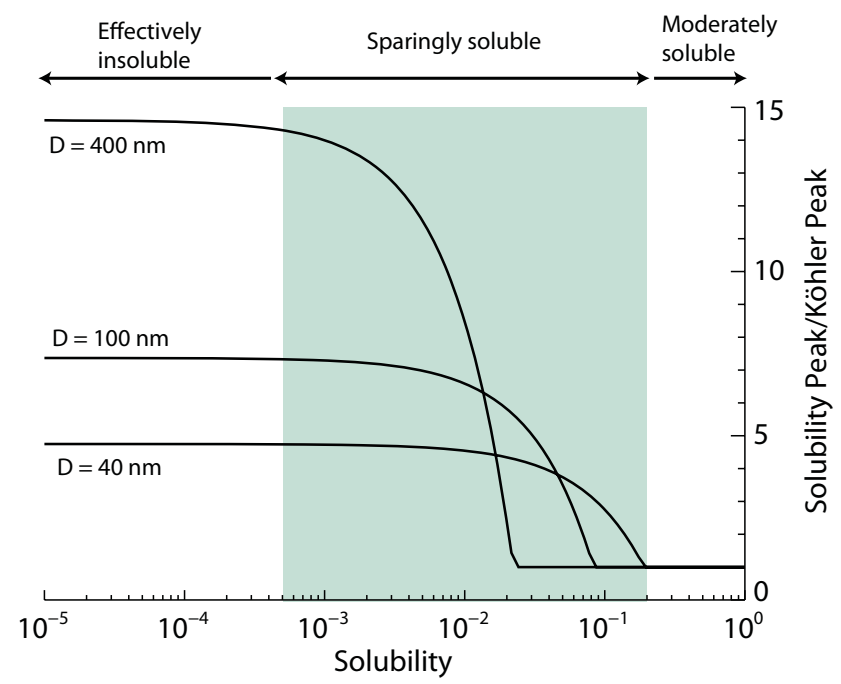

Fig. 3. Ratio of solubility peak to classical Köhler peak with solubility $C_{1}$ for particles having assumed $\kappa_{1}=0.23$ (succinic acid) and dry diameters of 400,100 , and $40 \mathrm{~nm}$ (solid lines). The ratio is set to unity if the Köhler peak dominates and cloud drop activation proceeds via classical theory. The plot delineates three solubility regimes that impact $\mathrm{CCN}$ activity in the size range $40<D_{\text {dry }}<400 \mathrm{~nm}$ : (1) $C<\sim 5 \times 10^{-4}$, where solubility of that compound is negligible, regardless of the value of $\kappa$, and the compound may be treated as effectively insoluble. (2) $C>\sim 2 \times 10^{-1}$ where $\mathrm{DRH}<s_{C}$ and cloud droplet activation is determined by particle hygroscopicity. (3) $2 \times 10^{-1}>C>5 \times 10^{-4}$ where cloud droplet activation is highly sensitive to particle solubility.

composed of an effectively insoluble single component, because the solubility is so small that partial dissolution is unimportant. In fact, the sodium chloride/calcium carbonate mixed particle hygroscopicity is well approximated by $\varepsilon_{1} \kappa_{1}=0.001 \times 1.28=0.00128$ (dashed line), treating the calcium carbonate $\kappa=0$.

Although Figs. (1) and (2) suggest that solubility can play an important role in cloud droplet activation, we argue that it is sufficient to classify a component as effectively infinitely soluble or effectively insoluble. Figure 3 shows the variation of the ratio of solubility peak $\left(s_{c 1}\right)$ and classical Köhler peak $\left(s_{c 2}\right)$ with solubility for a range of dry diameters for single component particles. For convenience we consider this ratio equal to unity when the classical Köhler peak exceeds the solubility peak, i.e. $s_{c 1}<s_{c 2}$. Figure 3 shows that sensitivity to solubility emerges only in the regime $\sim 2 \times 10^{-1}>C>5 \times 10^{-4}$, where the solubility values are expressed as volume of solute per unit volume of water present in a saturated solution. The presence of moderatelysoluble hygroscopic compounds in mixtures shifts this range to smaller solubilties. Figure 4 shows Köhler curves for binary mixtures of sodium chloride (5\% by volume) and organic compounds having the hygroscopicity of succinic acid and various solubilities for two initial dry diameters. For the 

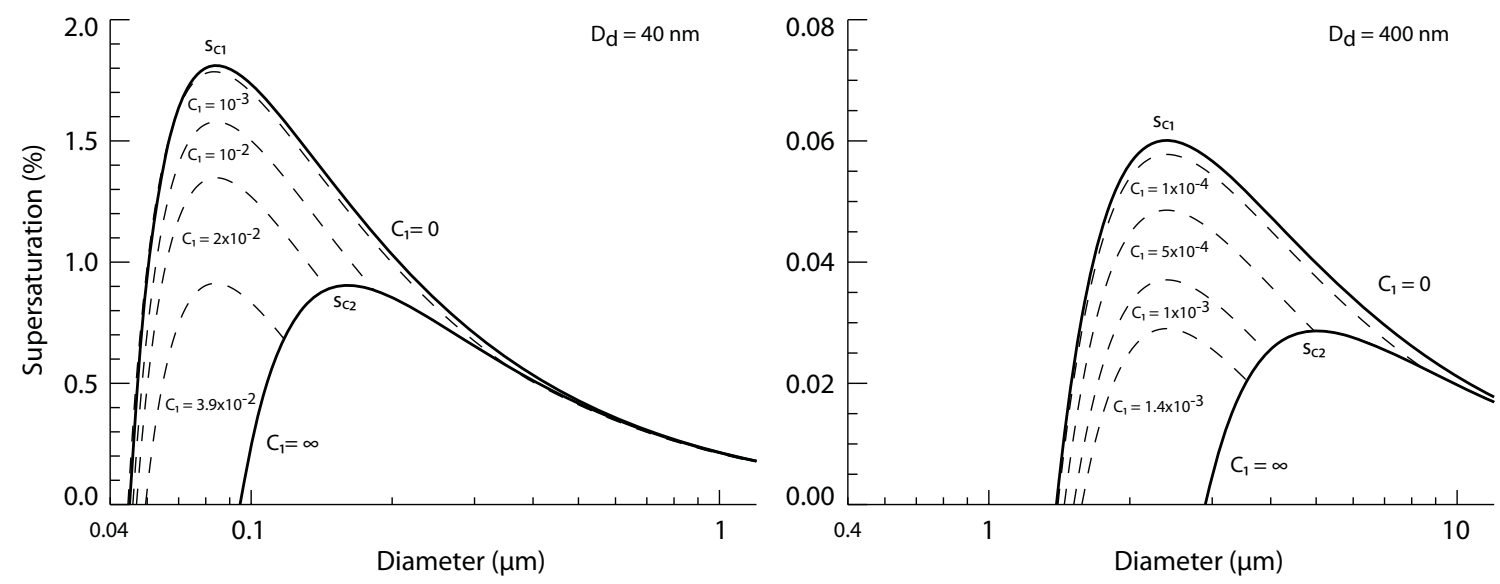

Fig. 4. Köhler curves for a compound having $\kappa_{1}=0.23$ (succinic acid) mixed with $5 \%$ sodium chloride by volume for a $40 \mathrm{~nm}$ (left) and $400 \mathrm{~nm}$ (right) dry diameter. The solubility of the succinic acid is varied over the interval $0<C<\infty$. The dashed lines indicate the range of values where solubility is an important determinant for the particles' critical supersaturation.

$400 \mathrm{~nm}$ dry particle, $C>10^{-3}$ implies that $s_{c 2}>s_{c 1}$ and thus that the sparingly soluble compound is completely dissolved at the point of activation. The range where the sensitivity to solubility emerges depends in principle on the particle dry diameter, the component hygroscopicities and solubilities and their respective volume fractions in the mixture. Although we have not fully explored the parameter space we believe that $2 \times 10^{-1}>C>5 \times 10^{-4}$ is a fairly conservative estimate of the range where solubility is important, thereby defining effectively insoluble compounds $\left(C<5 \times 10^{-4}\right)$, sparingly soluble compounds $\left(5 \times 10^{-4}<C<2 \times 10^{-1}\right)$, and moderately soluble compounds $\left(C>2 \times 10^{-1}\right)$. This classification is similar to that given by Hori et al. (2003) who introduced type $\mathrm{A}, \mathrm{B}$, and $\mathrm{C}$ aerosols. Type A particles are sparingly soluble and exhibit two local maxima, while type $\mathrm{B}$ is insoluble and type $C$ is very soluble. Since only a few pure compounds fall in the type A, or sparingly soluble range (e.g. succinic acid or ammonium oxalate as shown by Hori et al., 2003) and those only make up a small fraction of the total organic fraction, the off-isoline behavior seen for the pure sparinglysoluble compounds is likely of little atmospheric relevance. Nevertheless we stress that not all organic compounds in the atmospheric aerosol have been identified, leaving a potential role for type A aerosols in cloud droplet activation. A single kappa with contributions from insoluble compounds (modeled as $\kappa=0$ ) and infinitely soluble compounds (modeled according to their respective $\kappa_{i}$ ) can generally be used to describe ambient particles. However, solubility may be important in understanding measured CCN activity obtained for pure compounds in the laboratory.

\section{Appendix A}

In the case of multiple components with limited solubility, analytical approximations to Eqs. (9) and (10) do not exist and the maximum must be found numerically. Since multiple maxima can exist, gradient-based search algorithms may terminate at a local, and not the global, maximum. Thus the entire domain must be searched efficiently. We provide an implementation of our algorithm in the scripting language Python in Table A1. Python is a powerful high-level objectoriented scripting language that is available for all major computing platforms and is distributed at no cost under the GNU public license. The algorithm calculates the critical saturation ratio using a single dry diameter as input. Input and outputs are listed in detail in Table A2. Arrays containing any number of components having properties of $\kappa_{i}, \varepsilon_{i}$, and $C_{i}$ can be passed to the algorithm. Optionally temperature and surface tension values as well as parameters constraining the accuracy of the algorithm can be modified in the function call. The algorithm scans the wet diameter (or growth factor) in geometric increments given by "inc" until a termination criterion "gmax" is reached, and returns the maximum value found. Decreasing 'inc' allows for arbitrary accuracy of the returned solution, although accuracy is limited by the maximum recursion depth of the interpreter. The number of iterations per function call are given by $\ln (\operatorname{gmax}) / \ln$ (inc). We find that $\operatorname{gmax}=10$ and inc $=1.01$ give generally satisfactory results, thereby limiting the number of iterations to $\sim 200$. Program flow control is recursive to minimize the computational overhead and optimize the algorithm for speed. Table A3 gives two example calls to the function "Sc" defined in Table A1. Example 1 is a $100 \mathrm{~nm}$ particle that is composed in equal proportions of two components having $\kappa=0.6$ and $\kappa=0.2$. The compound with $\kappa=0.6$ is infinitely soluble while the substance having $\kappa=0.2$ is sparingly soluble, i.e. $C=0.1$. Default parameters of the algorithm are not modified. Example 2 is a single component system having $\kappa=0.6$ and is infinitely soluble. The calculation is performed at $273 \mathrm{~K}$ instead of the default temperature. 
Table A1. Python implementation of the algorithm to numerically find the critical saturation ratio for a specified dry diameter. Note that the "dot" function performs the dot product on two vectors and is imported from the numerical python (NumPy) library. The "exp" function is imported from the math library. All remaining functions are built into Python. Explanations for variables used are given in Table 2. Example function calls are summarized in Table 3. Lines starting with the \# symbol indicate comments.

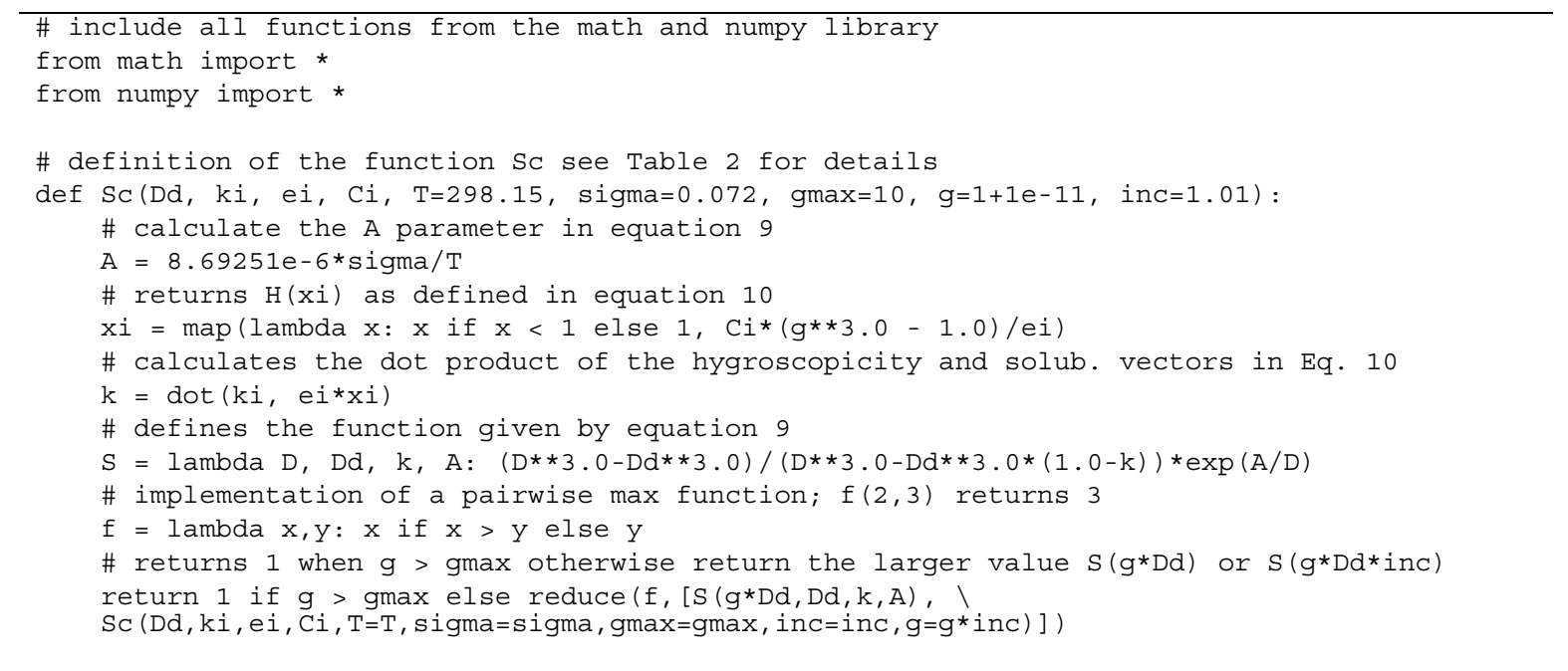

Table A2. Variable definitions, types, definition, units, inputs and outputs (I/O) for the function Sc shown in Table 1. Array inputs take values for each specified compound. Some inputs have a predefined value while retaining the option of a user defined input. N/A denotes not applicable.

\begin{tabular}{lllllll}
\hline Variable & Type & Definition & Units & $\mathrm{I} / \mathrm{O}$ & Optional & Default \\
\hline $\mathrm{Dd}$ & scalar & dry diameter & $\mathrm{m}$ & in & no & $\mathrm{N} / \mathrm{A}$ \\
$\mathrm{ki}$ & array & hygroscopicity & unitless & in & no & $\mathrm{N} / \mathrm{A}$ \\
$\mathrm{ei}$ & array & volume fraction of solute in mixture & unitless & in & no & $\mathrm{N} / \mathrm{A}$ \\
$\mathrm{Ci}$ & array & solubility (volume solute/volume water) & unitless & in & no & $\mathrm{N} / \mathrm{A}$ \\
$\mathrm{T}$ & scalar & temperature & $\mathrm{K}$ & in & yes & 298.15 \\
sigma & scalar & solution surface tension & $\mathrm{N} \mathrm{m}^{-2}$ & in & yes & 0.072 \\
gmax & scalar & maximum growth factor considered & unitless & in & yes & 10 \\
$\mathrm{~g}$ & scalar & initial growth factor considered & unitless & in & yes & $1+10^{-11}$ \\
inc & scalar & growth factor increment & unitless & in & yes & 1.01 \\
Sc & scalar & critical saturation ratio & unitless & out & no & N/A \\
\hline
\end{tabular}

Table A3. Example calls to the Python function sc shown in Table 1. The string "inf" is the Python representation for infinity. See text and Table 2 for details.

\begin{tabular}{|c|c|c|c|c|}
\hline Description & $\mathrm{Dd}$ & hygroscopicity & volume fraction & solubility \\
\hline Example 1 & $\mathrm{Sc}(100 \mathrm{e}-9$ & $\operatorname{array}([0.6,0.2])$, & $\operatorname{array}([0.5,0.5])$, & [inf,0.1])) \\
\hline Example 2 & $\mathrm{Sc}(100 \mathrm{e}-9$ & $\operatorname{array}([0.6]), \operatorname{arr}$ & $([1]), \operatorname{array}([i]$ & $=273.01$ \\
\hline
\end{tabular}


Acknowledgements. This work was funded by the National Science Foundation under grant ATM-0436196. SMK acknowledges funding from the NOAA climate goal.

Edited by: S. Pandis

\section{References}

Asa-Awuku, A. and Nenes, A.: Effect of solute dissolution kinetics on cloud droplet formation: Extended Köhler theory, J. Geophys. Res., 112, D22201, doi:10.1029/2005JD006934, 2007.

Bilde, M. and Svenningsson, B.: CCN activation of slightly soluble organics: The importance of small amounts of inorganic salt and particle phase, Tellus, 56B, 128-134, 2004.

Broekhuizen, K., Kumar, P. P., and Abbatt, J. P. D.: Partially soluble organics as cloud condensation nuclei: Role of trace soluble and surface active species, Geophys. Res. Lett., 31, L01107, doi:10.1029/2003GL018203, 2004.

Henning, S., Rosenorn, T., D’ Anna, B., Gola, A. A., Svenningsson, B., and Bilde, M.: Cloud droplet activation and surface tension of mixtures of slightly soluble organics and inorganic salt, Atmos. Chem. Phys., 5, 575-582, 2005, http://www.atmos-chem-phys.net/5/575/2005/.

Hori, M., Ohta, S., Murao, N., and Yamagata, S.: Activation capability of water soluble organic substances as CCN, J. Aerosol. Sci., 34, 419-448, 2003.

Kelly, J. T., Chuang, C. C., and Wexler, A. S.: Influence of dust composition on cloud droplet formation, Atmos. Environ., 41, 2904-2916, 2007.

Kreidenweis, S. M., Petters, M. D., and DeMott, P. J.: Deliquescence-controlled activation of organic aerosols, Geophys. Res. Lett., 33, L06801, doi:10.1029/2005GL024863, 2006.
Laaksonen, A., Korhonen, P., Kulmala, M., and Charlson, R. J.: Modification of the Köhler equation to include soluble trace gases and slightly soluble substances, J. Atmos. Sci., 55, 853862, 1998.

Padró, L. T. and Nenes, A.: Cloud droplet activation: solubility revisited, Atmos. Chem. Phys. Discuss., 7, 2325-2355, 2007, http://www.atmos-chem-phys-discuss.net/7/2325/2007/.

Petters, M. D. and Kreidenweis, S. M.: A single parameter representation of hygroscopic growth and cloud condensation nucleus activity, Atmos. Chem. Phys., 7, 1961-1971, 2007, http://www.atmos-chem-phys.net/7/1961/2007/.

Rissler, J., Vestin, A., Swietlicki, E., Fisch, G., Zhou, J., Artaxo, P., and Andreae, M. O.: Size distribution and hygroscopic properties of aerosol particles from dry-season biomass burning in Amazonia, Atmos. Chem. Phys., 6, 471-491, 2006, http://www.atmos-chem-phys.net/6/471/2006/.

Raymond, T. M. and Pandis, S. N.: Formation of cloud droplets by multicomponent organic particles, J. Geophys. Res., 108, 4469, doi:10.1029/2003JD003503, 2003.

Shulman, M. L., Jacobson, M. C., Charlson, R. J., Synovec, R. E., and Young, T. E.: Dissolution behavior and surface tension effects of organic compounds in nucleating cloud droplets, Geophys. Res. Lett., 23, 277-280, 1996.

VanReken, T. M., Ng, N. L., Flagan, R. C., and Seinfeld, J. H.: Cloud condensation nucleus activation properties of biogenic secondary organic aerosol, J. Geophys. Res., 110, D07206, doi:10.1029/2004JD005465, 2005.

Ziese, M., Wex, H., Nilsson, E., Salma, I., Ocskay, R., Hennig, T., Massling, A., and Stratmann, F.: Hygroscopic growth and activation of HULIS particles: experimental data and a new iterative parameterization scheme for complex aerosol particles, Atmos. Chem. Phys., 8, 1855-1866, 2008, http://www.atmos-chem-phys.net/8/1855/2008/. 